\title{
PENGGUNAAN METODE PARTICLE SWARM OPTIMIZATION (PSO) PADA OPTIMASI MULTIRESPON GAYA TEKAN DAN MOMEN TORSI PENGGURDIAN MATERIAL KOMPOSIT GLASS FIBER REINFORCE POLYMER (GFRP) YANG DITUMPUK DENGAN MATERIAL STAINLESS STEEL (SS)
}

\author{
Angga Sateria ${ }^{1}$, Indra Dwi Saputra², Yuli Dharta ${ }^{3}$ \\ 1,3Jurusan Teknik Mesin - Politeknik Manufaktur Negeri Bangka Belitung \\ ${ }^{2} J u r u s a n$ Teknik Elektronika - Politeknik Manufaktur Negeri Bangka Belitung \\ Kawasan Industri Airkantung Sungailiat, \\ Telp.0717-93586, Fax.0717-93585, anggasateria@gmail.com
}

\begin{abstract}
The Particle Swarm Optimization (PSO) method is one of the methods used for multirespon optimization in the manufacturing process. In this research, the material used is Glass fiber reinforced polymer (GFRP) composite material which is stacked with stainless steel material. The machining process used is a drilling process conducted on a vertical CNC machine Brother TC-22A-O. The thrust force and torque is the response used to evaluate the performance of the drilling process. The quality characteristics of this response "the smaller the better". The aim of this study was to identify the combination of process parameters to achieve the performance characteristics required in drilling process the GFRP-SS material using Particle Swarm Optimization methode (PSO). The three process parameters i.e. point angle, spindle speed, and feeding speed is used as a process parameter. Point angle was set at two different levels, while the other two were set at three different levels. Therefore, the $2 \times 3 \times 3$ factorial is used as the experimental design. The experiments were replicated two times. The minimum thrust force and torque could be obtained by using point angle, spindle speed, and feeding speed are $118^{\circ}, 2330 \mathrm{rpm}$, and $65 \mathrm{~mm} / \mathrm{min}$ respectively.
\end{abstract}

Keywords: Drilling process, GFRP-SS material, particle swarm optimization, multiresponse optimization.

\begin{abstract}
Abstrak
Metode Particle Swarm Optimization (PSO) adalah salah satu metode yang digunakan untuk optimasi multirespon pada proses manufaktur. Pada penelitian ini, material yang digunakan adalah Material komposit Glass fiber reinforced polymer (GFRP) yang direkatkan dengan material baja tahan karat (stainless steel). Proses pemesinan yang digunakan adalah proses gurdi yang dilakukan pada mesin CNC vertikal Brother TC-22A-O. Gaya tekan dan momen torsi adalah respon yang digunakan untuk mengevaluasi kinerja proses gurdi tersebut. Karakteristik kualitas dari respon ini "semakin kecil semakin baik". Tujuan dari penelitian ini adalah untuk mengidentifikasi kombinasi parameter-parameter proses untuk mencapai karakteristik kinerja yang diperlukan dalam proses penggurdian material GFRP-SS menggunakan metode particle swarm optimization (PSO). Tiga parameter proses yang dipilh yaitu sudut ujung pahat, kecepatan spindel,dan kecepatan makan digunakan sebagai parameter proses. Sudut ujung pahat memiliki dua level, kecepatan spindel dan kecepatan makan memiliki tiga level. Oleh karena itu, faktorial 2 × 3 × 3 digunakan sebagai design eksperimen. Eksperimen direplikasi sebanyak dua kali. Gaya tekan dan momen torsi yang minimum dapat diperoleh dengan menggunakan sudut ujung pahat, kecepatan spindel,dan kecepatan makan masing-masing adalah $118^{\circ}, 2330 \mathrm{rpm}$, dan $65 \mathrm{~mm} / \mathrm{menit}$.
\end{abstract}

Kata kunci: Proses gurdi, material GFRP-SS, particle swarm optimization, optimasi multirespon.

\section{PENDAHULUAN}

Material komposit glass fiber reinforce polymer (GFRP) yang ditumpuk dan direkatkan dengan material baja tahan karat (stainless steel) umumnya digunakan dalam komponen struktur pesawat terbang termasuk bagian sayap dan bagian badan pesawat. Perakitan material tersebut biasanya

Penggunaan Metode PSO Pada Optimasi Multirespon Gaya Tekan dan Momen Torsi Penggurdian Material Komposit GFRP Yang Ditumpuk Dengan Material Stainless Steel (Angga Sateria) 
memerlukan penyambungan mekanik (baut dan mur) dan dibutuhkan proses penggurdian untuk membuat lubang pada material tersebut [1]. Selain persyaratan toleransi lubang sangat penting, juga harus diperhatikan umur dari pahat gurdi supaya dapat memproduksi lubang yang banyak dengan menggunakan sedikit pahat gurdi. Hal yang mempengaruhi kualitas lubang dan umur dari pahat gurdi tersebut adalah besarnya gaya tekan dan momen torsi yang terjadi pada saat proses penggurdian [2]. Gaya tekan dan momen torsi adalah dua dari beberapa respon yang digunakan untuk mendapatkan kualitas lubang yang baik dalam penggurdian material GFRP/SS. Kedua respon harus minimum untuk mendapatkan kualitas lubang yang tinggi. Parameter pemesinan dan geometri pahat biasanya dipilih berdasarkan pengalaman operator atau pedoman yang diusulkan dari pabrikan. Pada proses pemesinan secara umum, Parameter pemesinan yang mempengaruhi karakteristik kualitas ataupun ukuran-ukuran kinerja adalah kecepatan spindel, kecepatan makan, geometri dan sudut ujung pahat (point angle) [3,4]. Optimasi parameter proses pemesinan akan meningkatkan kualitas produk dan produktifitas kerja.

Metode yang populer dalam beberapa tahun terakhir untuk menyelesaikan permasalahan optimasi adalah metode jaringan syaraf tiruan atau artificial neural network (ANN) digabungkan dengan particle swarm optimization (PSO). ANN merupakan algoritma pembelajaran pada artificial neural network (ANN) yang berfungsi untuk mempelajari hubungan antara parameter proses (input) dengan respon (output), sehingga ANN mampu melakukan prediksi terhadap nilai respon yang akan didapat dengan menggunakan parameter proses yang ditentukan. Salah satu metode yang sering digunakan untuk menyelesaikan permasalahan optimasi multi respon adalah metode PSO. PSO mampu mengidentifikasi nilai optimum secara global dengan keakuratan yang tinggi [5]. Penggabungan metode ANN dengan PSO mampu digunakan untuk memprediksi dan menentukan parameter optimal yang menghasilkan gaya tekan torsi yang minimal pada proses pemesinan gurdi.

\section{METODE PENELITIAN}

Langkah-langkah penelitian ini ditunjukkan pada diagram alir berikut:
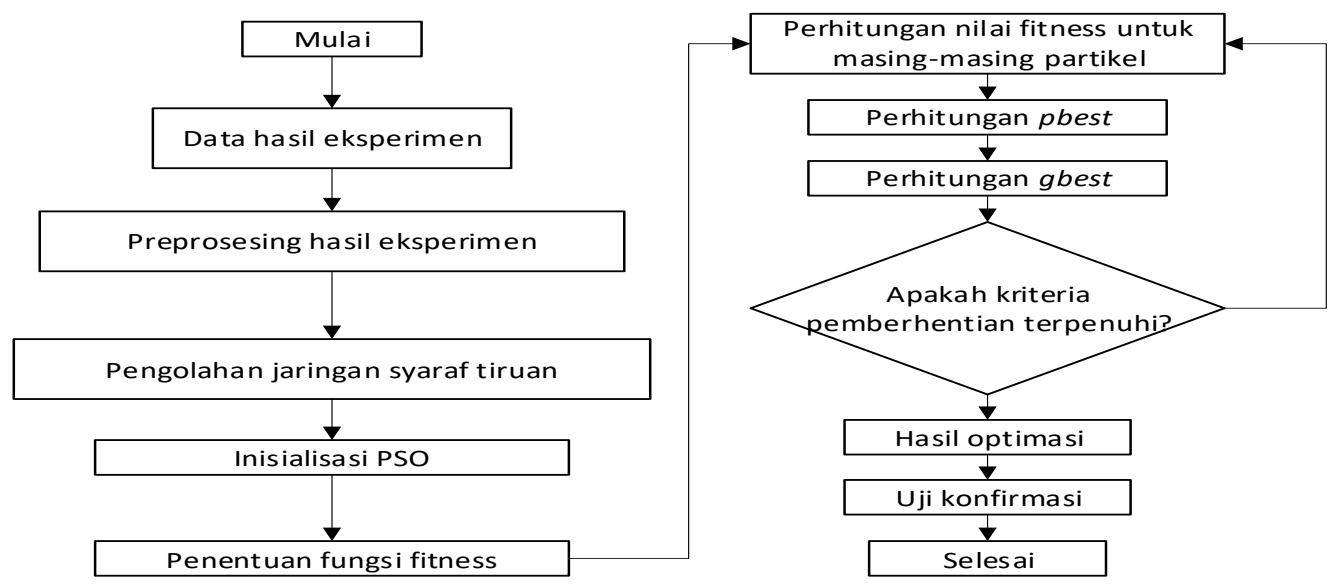

Gambar 1 Diagram alir penelitian

\section{Material dan skema penggurdian}

Material yang digunakan pada penelitian ini adalah material baja tahan karat (stainless steel) yang ditumpuk dan direkatkan dengan material komposit GFRP. Spesimen benda kerja memiliki ukuran $200 \times 30 \times 5,3 \mathrm{~mm}$. Tebal masing-masing material adalah stainless steel $=1,2 \mathrm{~mm}, \mathrm{GFRP}=4 \mathrm{~mm}$, dan resin $=0.1 \mathrm{~mm}$. Posisi material stainless steel berada diatas dan material GFRP berada dibawah. Kedua material ini ditumpuk dan direkatkan dengan menggunakan resin jenis Loctite EA 934NA. Gambar 2 menunjukkan skema proses penggurdian GFRP-SS. Pahat gurdi yang digunakan dalam penelitian ini adalah two flute straight twist drill yang terbuat dari material karbida yang memiliki diameter $8 \mathrm{~mm}$ dan sudut helik $30^{\circ}$. Penggurdian dilakukan pada mesin CNC vertikal Brother TC-22A-O dan dilakukan tanpa menggunakan pendingin. Gaya tekan $(\mathrm{Fz})$ dan momen torsi $(\mathrm{Mz})$ diukur dengan menggunakan dinamometer KISTLER tipe 9272. 


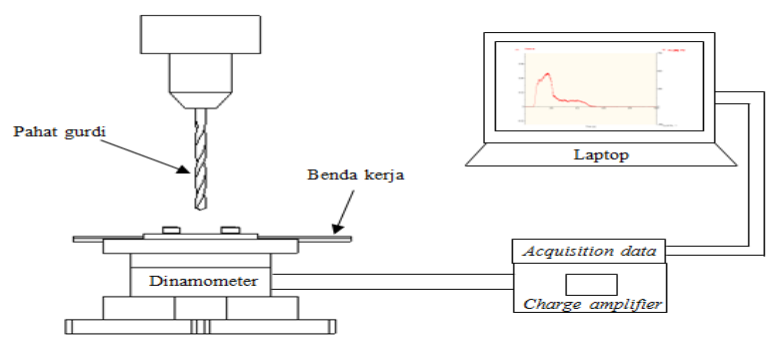

Gambar 2 Skema proses penggurdian material GFRP-SS

\section{Desain Eksperimen.}

Terdapat tiga parameter proses yang digunakan pada penelitian ini. Parameter proses yang dipilih adalah sudut ujung pahat, kecepatan makan dan kecepatan spindel. Parameter proses dan masingmasing level yang digunakan dalam penelitian ini ditunjukkan pada Tabel 1. Pada desain eksperimen, dua parameter mempunyai tiga level dan satu parameter mempunyai dua level. Rancangan seperti ini bisa juga disebut desain faktorial $2 \times 3 \times 3$ [6]. Jumlah kombinasi faktor adalah sebanyak 18. Akan ada dua pengulangan/replikasi yang dilakukan untuk setiap percobaan untuk memperkirakan ketidakpastian hasilnya. Oleh karena itu, jumlah pengamatan adalah sebanyak 36. Respon-respon yang diamati pada penelitian ini adalah gaya tekan dan momen torsi. Rancangan percobaan dan hasil percobaan ditunjukkan pada Tabel 2.

Tabel 1. Parameter proses dan masing-masing level

\begin{tabular}{|c|c|c|c|c|}
\hline Parameter proses & Unit & $\begin{array}{c}\text { Level } \\
\mathbf{1}\end{array}$ & $\begin{array}{c}\text { Level } \\
\mathbf{2}\end{array}$ & $\begin{array}{c}\text { Level } \\
\mathbf{3}\end{array}$ \\
\hline Sudut ujung pahat (PA) & derajat & 118 & 130 & - \\
\hline Kecepatan spindel (SS) & $\mathrm{rpm}$ & 600 & 1500 & 2400 \\
\hline Kecepatan makan (FS) & $\mathrm{mm} / \mathrm{min}$ & 60 & 90 & 120 \\
\hline
\end{tabular}

Table 2. Desain eksperimen dan hasil eksperimen

\begin{tabular}{|c|c|c|c|c|c|c|c|}
\hline \multirow{2}{*}{ No } & \multicolumn{3}{|c|}{$\begin{array}{c}\text { Parameter } \\
\text { proses }\end{array}$} & \multicolumn{2}{c|}{ Fz (N) } & \multicolumn{2}{|c|}{ Mz (Nm) } \\
\cline { 2 - 8 } & PA & SS & FS & R1 & R2 & R1 & R2 \\
\hline 1 & 1 & 1 & 1 & 232,80 & 234,30 & 3,035 & 3,187 \\
\hline 2 & 1 & 1 & 2 & 291,20 & 315,20 & 4,594 & 3,976 \\
\hline 3 & 1 & 1 & 3 & 350,30 & 370,20 & 5,350 & 5,666 \\
\hline 4 & 1 & 2 & 1 & 152,60 & 160,40 & 2,195 & 2,018 \\
\hline 5 & 1 & 2 & 2 & 235,50 & 230,20 & 2,900 & 2,824 \\
\hline 6 & 1 & 2 & 3 & 290,40 & 284,20 & 3,591 & 3,614 \\
\hline 7 & 1 & 3 & 1 & 109,20 & 109,40 & 1,597 & 1,551 \\
\hline 8 & 1 & 3 & 2 & 190,80 & 182,50 & 2,074 & 1,911 \\
\hline 9 & 1 & 3 & 3 & 250,90 & 257,50 & 2,708 & 2,672 \\
\hline 10 & 2 & 1 & 1 & 293,10 & 309,90 & 2,828 & 2,941 \\
\hline 11 & 2 & 1 & 2 & 379,00 & 344,90 & 4,085 & 4,064 \\
\hline 12 & 2 & 1 & 3 & 424,60 & 437,20 & 5,331 & 5,211 \\
\hline 13 & 2 & 2 & 1 & 212,40 & 224,10 & 1,793 & 1,855 \\
\hline 14 & 2 & 2 & 2 & 288,10 & 279,20 & 2,571 & 2,246 \\
\hline 15 & 2 & 2 & 3 & 349,70 & 358,60 & 3,280 & 3,261 \\
\hline 16 & 2 & 3 & 1 & 175,50 & 163,70 & 1,334 & 1,282 \\
\hline 17 & 2 & 3 & 2 & 249,20 & 240,00 & 1,631 & 1,678 \\
\hline 18 & 2 & 3 & 3 & 300,70 & 314,40 & 2,220 & 2,390 \\
\hline
\end{tabular}




\section{Optimasi Multirespon Menggunakan Particle Swarm Optimization (PSO)}

\section{- Penetuan fungsi fitnes (fitness function)}

Pada penelitian ini, fungsi fitnes didapatkan dengan menggunakan jaringan syaraf tiruan. Fungsi fitnes didapatkan dengan menggabungkan dua fungsi objektif (objective function) menjadi satu fungsi fitnes (fitness function) [7]. Fungsi objektif dari masing-masing respon didapatkan dengan menggunakan persamaan berikut:

$$
\begin{aligned}
O b j_{k} & =\left(\sum_{j=1}^{13} v_{j k} \cdot\left(\left(\frac{2}{1+e^{-2 z}}\right)-1\right)\right)+v 0_{k} \\
z & =\left(\sum_{j=1}^{15}\left(u_{i j} \cdot x_{i}\right)\right)+u 0_{j}
\end{aligned}
$$

Dengan:

$$
\begin{aligned}
& \mathrm{Obj}_{l}=\text { Respon dari eksperimen, yaitu gaya tekan dan torsi. } \quad v \quad=\text { nilai bobot dari dari hidden layer ke output layer } \\
& i=\text { jumlah parameter proses. } \quad u_{0}=\text { nilai bias dari dari input layer ke hidden layer. } \\
& j=\text { jumlah neuron pada hidden layer. } \quad v_{0}=\text { nilai bias dari dari hidden layer ke output layer } \text {. }
\end{aligned}
$$

\section{- Metode Particle Swarm Optimization (PSO)}

Particle Swarm Optimization (PSO) merupakan metode optimasi yang dapat digunakan untuk menentukan parameter-parameter proses yang menghasilkan nilai respon yang optimum. PSO meniru sosial perilaku sekawanan burung atau ikan pada habitat alami. Setiap individu atau partikel berperilaku dengan cara menggunakan kecerdasannya (intelligence) sendiri dan juga dipengaruhi perilaku kelompok kolektifnya. Saat satu partikel atau seekor burung menemukan jalan yang tepat atau pendek menuju ke sumber makanan, sisa kelompok yang lain juga akan dapat segera mengikuti jalan tersebut meskipun lokasi mereka jauh di kelompok tersebut. Setiap individu atau partikel diperlakukan seperti sebuah titik pada suatu dimensi ruang tertentu. Terdapat dua faktor yang memberikan karakter terhadap status partikel pada ruang pencarian yaitu posisi partikel dan kecepatan partikel [8]. Berikut merupakan formulasi matematika yang menggambarkan posisi dan kecepatan partikel pada suatu dimensi ruang tertentu:

$$
\begin{aligned}
& x_{j}(i)=x_{1}(1), x_{2}(1), \ldots, x_{j N}(i) \\
& v_{j}(i)=v_{1}(1), v_{2}(1), \ldots, v_{j N}(i)
\end{aligned}
$$

Dengan:

$$
\begin{aligned}
& x=\text { posisi partikel } \\
& v=\text { kecepatan partikel } \\
& i=\text { iterasi ke- } i \\
& j=\text { indeks partikel } \\
& N=\text { jumlah partikel }
\end{aligned}
$$

Persamaan untuk mekanisme pembaruan status partikel adalah sebagai berikut (Kennedy dan Eberhart, 1995):

$$
\begin{gathered}
v_{j}(i)=v_{j}(i-1)+c_{1} r_{1}\left(P_{b e s t, j}-x_{j}(i-1)\right)+c_{2} r_{2}\left(G_{\text {best }}-x_{j}(i-1)\right) \\
x_{j}(i)=v_{j}(i)+x_{j}(i-1)
\end{gathered}
$$

Dengan:

$j \quad=1,2, \ldots, N$ merepresentasikan jumlah partikel

$\mathrm{Obj}_{i}=$ respon dari eksperimen yaitu gaya tekan, torsi, delaminasi lubang masuk dan delaminasi lubang keluar.

$P_{\text {best }, j}=P_{\text {best }, 1}, P_{\text {best }, 2}, \ldots, P_{\text {best }, 2}$ merepresentasikan personal best dari partikel ke-j

$G_{\text {best }}=$ merepresentasikan global best dari seluruh kawanan.

$c_{1}, c_{2}=$ learning factor 
$r_{1}, r_{2}=$ konstanta berupa bilangan random yang bernilai antara 0 sampai 1 .

Persamaan (5) digunakan untuk menghitung kecepatan partikel yang baru berdasarkan kecepatan sebelumnya, jarak antara posisi saat ini dengan posisi terbaik partikel (personal best) dan jarak antar posisi saat ini dengan posisi terbaik kawanan ( $g$ lobal best). Partikel kemudian berpindah menuju posisi yang baru berdasarkan persamaan (6). Algoritma PSO ini dijalankan dengan sejumlah iterasi tertentu hingga mencapai kriteria pemberhentian, sehingga akan didapatkan solusi yang terletak pada global best. Persamaan ini akan disimulasikan dalam ruang dengan dimensi tertentu dengan sejumlah iterasi, sehingga di setiap iterasi posisi partikel akan semakin mengarah ke target yang dituju (minimalisasi atau maksimalisasi nilai fungsi). Hal ini dilakukan hingga maksimum iterasi dicapai atau tercapainya kriteria pemberhentian yang lain.

\section{HASIL DAN PEMBAHASAN}

\section{- Pengaruh parameter proses gurdi terhadap hasil gaya tekan dan torsi}

Pengaruh kecepatan spindel dan kecepatan makan (feeding) terhadap gaya tekan dan torsi ditunjukkan pada Gambar 3. Pada Gambar 3 (a dan c) ditunjukkan bahwa peningkatan kecepatan makan akan meningkatkan gaya tekan dan torsi pada penggurdian dengan menggunakan sudut ujung pahat sebesar $118^{\circ}$. Sedangkan peningkatan kecepatan spindel akan menurunkan besarnya gaya tekan dan torsi seperti ditunjukkan pada Gambar 3 (b dan d). Peningkatan kecepatan spindel akan meningkatkan gesekan antara pahat gurdi dengan material stainless steel, sehingga meningkatkan temperatur pemotongan. Kenaikan dari temperatur pemotongan ini akan menyebabkan pelunakan terhadap material sehingga gaya tekan yang dihasilkan akan menurun [9].

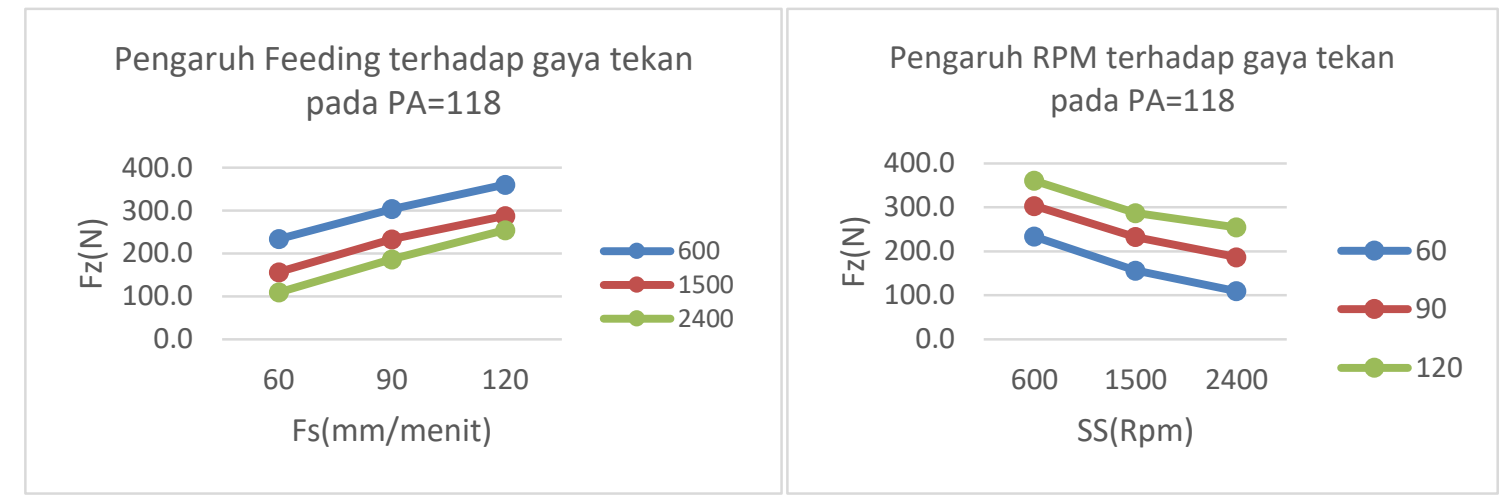

(a)

(b)

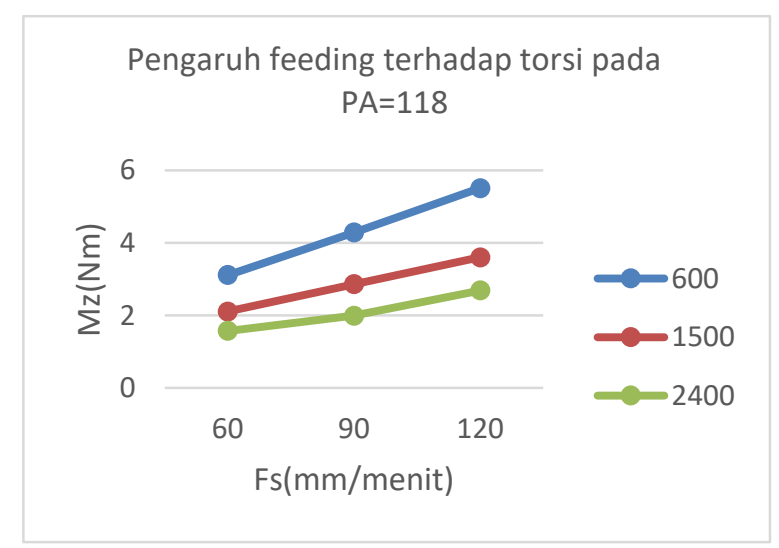

(c)

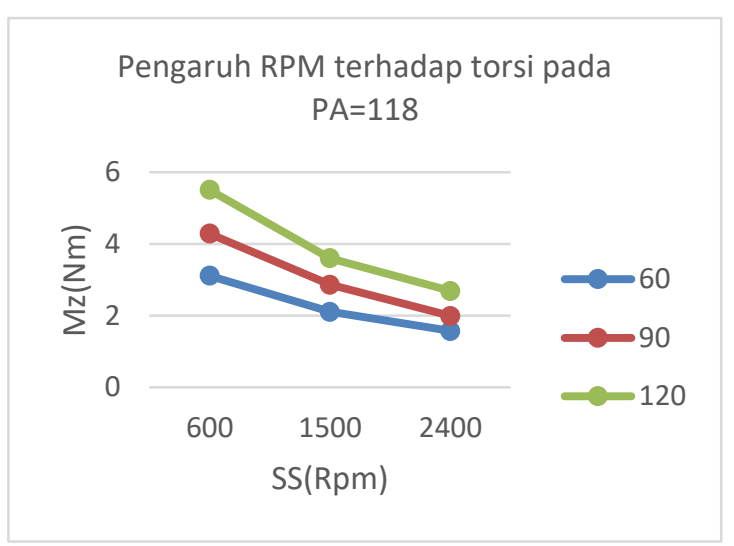

(d)

Gambar 3 Pengaruh kecepatan spindel dan feeding terhadap gaya tekan dan torsi 
- Optimasi parameter dengan menggunakan metode PSO

Parameter proses yang didapatkan dari optimasi PSO dan respon yang diprediksi dengan menggunakan jaringan syaraf tiruan ditunjukkan pada Tabel 3. Seting yang dipilih adalah seting yang menghasilkan respon yang paling kecil untuk ke dua respon.

Tabel 3 Hasil seting optimasi PSO dan prediksi JST

\begin{tabular}{|c|c|c|c|c|}
\hline \multicolumn{3}{|c|}{ Process Parameters } & \multicolumn{2}{c|}{ Prediksi Respon } \\
\hline $\begin{array}{c}\text { Sudut ujung } \\
\text { pahat }\end{array}$ & $\begin{array}{c}\text { Kecepatan } \\
\text { spindel }\end{array}$ & $\begin{array}{c}\text { Kecepatan } \\
\text { makan }\end{array}$ & $\begin{array}{c}\text { Gaya tekan } \\
(\mathrm{N})\end{array}$ & $\begin{array}{c}\text { Momen torsi } \\
(\mathrm{Nm})\end{array}$ \\
\hline 118 & 2330 & 65 & 115,322 & 1,680 \\
\hline
\end{tabular}

Optimasi multirespon dengan menggunakan metode PSO menghasilkan sudut ujung pahat sebesar $118^{\circ}$, kecepatan spindel sebesar $2330 \mathrm{rpm}$ dan kecepatan makan sebesar $65 \mathrm{~mm} / \mathrm{menit}$. Prediksi respon dengan menggunakan JST menghasilkan gaya tekan sebesar 115,322 N, dan momen torsi sebesar $1,680 \mathrm{Nm}$.

\section{- Eksperimen konfirmasi}

Eksperimen konfirmasi dilakukan untuk membandingkan hasil prediksi JST dengan hasil eksperimen. Eksperimen konfirmasi direplikasi sebanyak tiga kali. Seting parameter proses pada eksperimen konfirmasi sesuai dengan hasil optimasi yang dilakukan dengan menggunakan metode PSO seperti ditunjukkan pada Tabel 3, yaitu sudut ujung pahat sebesar $118^{\circ}$, kecepatan spindel sebesar 2330 rpm, kecepatan makan sebesar $65 \mathrm{~mm} /$ menit. Pengukuran gaya tekan dan momen torsi dilakukan pada setiap replikasi. Hasil eksperimen konfirmasi dapat dilihat pada Tabel 4.

Tabel 4 Hasil eksperimen konfirmasi

\begin{tabular}{|c|c|c|c|c|}
\hline \multicolumn{2}{|c|}{ Parameter proses } & \multicolumn{2}{c|}{ Respon } \\
\hline \multirow{2}{*}{$\begin{array}{c}\text { Sudut ujung } \\
\text { pahat }\end{array}$} & $\begin{array}{c}\text { Kecepatan } \\
\text { spindel }\end{array}$ & $\begin{array}{c}\text { Kecepatan } \\
\text { makan }\end{array}$ & $\begin{array}{c}\text { Gaya tekan } \\
(\mathrm{N})\end{array}$ & $\begin{array}{c}\text { Momen torsi } \\
\text { (Nm) }\end{array}$ \\
\hline \multirow{2}{*}{118} & 2330 & \multirow{2}{*}{65} & 114,43 & 1,633 \\
\cline { 4 - 5 } & Rata-rata & 117,36 & 1,631 \\
\cline { 3 - 5 } & & 116,48 & 1,624 \\
\hline \multicolumn{3}{|c|}{} & 116,09 & 1,629 \\
\hline
\end{tabular}

Data hasil eksperimen konfirmasi menunjukkan bahwa nilai rata-rata respon yang dapat dicapai adalah gaya tekan sebesar 116,09 N, dan momen torsi sebesar 1,629 Nm.

\section{SIMPULAN}

Berdasarkan analisa hasil eksperimen dan proses optimasi yang telah dilakukan pada penelitian ini, dapat disimpulkan bahwa peningkatan kecepatan makan akan meningkatkan gaya tekan dan torsi Sedangkan peningkatan kecepatan spindel akan menurunkan besarnya gaya tekan dan torsi. Pengaturan parameter-parameter proses gurdi dengan menggunakan metode particle swarm optimization (PSO) yang dapat meminimumkan respon gaya tekan dan momen torsi secara serentak pada penggurdian material GFRP-stainless steel adalah sudut ujung pahat sebesar $118^{\circ}$, kecepatan spindel sebesar $2330 \mathrm{rpm}$ dan kecepatan makan sebesar $65 \mathrm{~mm} /$ menit,.

\section{DAFTAR PUSTAKA}

[1] I. S. Shyha, S. L. Soo, D. K. Aspinwall, S. Bradley, R. Perry. 2011. Hole Quality Assessment Following Drilling of Metallic-Composite Stacks. International Journal of Machine Tools and Manufacture, Vol. 51, No. 7, pp. 569-578. 
[2] Nagaraja, M. A. Herbert, D. Shetty, R. Shetty, B. Shivamurthy. 2013. Effect of Process Parameters on Delamination, Thrust Force, and Torque in Drilling of Carbon Fiber Epoxy Composite. Research Journal of Recent Sciences, Vol. 2, No. 8, pp: 47-51.

[3] Palanikumar, K. 2011, "Experimental Investigation and Optimisation in Drilling of GFRP Composites," Measurement, Vol. 44, No.10, hal. 2138-2148.

[4] Vankanti, V. K., dan Ganta, V. K. 2013. "Optimization of Process Parameters in Drilling of GFRP Composite Using Taguchi Method," Journal of Materials Research and Technology, Vol. 3, No. 1, hal. 35-41.

[5] Shunmugesh, K., dan Panneerselvam, K. 2016. "Machinability Study of Carbon Fiber Reinforced Polymer in the Longitudinal and Transverse Direction and Optimization of Process Parameters Using PSO-GSA," Engineering Science and Technology, an International Journal, Vol. 19, No.3, hal. 15521563.

[6] Montgomery, D. C. 2009. "Design and Analysis of Experiment," John Wiley and Sons, Inc., New York.

[7] Santosa, B., dan Willy, P. 2011. "Metoda Metaheuristik: Konsep dan Implementasi", Guna Widya, Surabaya.

[8] Kennedy, J., dan Eberhart, R. 1995. "Particle Swarm Optimization," Proceeding of IEEE International Conference on Neural Networks, Vol. 6.

[9] Armarago, E., J., A., Material Removal Processes-Twist Drills and Drilling Operation, The University of Melbourne, Melbourne.

[10] A. Sateria. 2017. “Optimasi Multirespon Gaya Tekan dan Momen Torsi pada Penggurdian Material Komposit Glass Fiber Reinforce Polymer (GFRP) yang ditumpuk dengan Material Stainless Steel (SS) Menggunakan Metode Algoritma Genetika" Jurnal Manutech-Polman Babel. 